\title{
Situação minoritária, população minorizada, língua menor: uma reflexão sobre a valoração do estatuto das línguas na situação de contato linguístico
}

Letícia Cao Ponso ${ }^{a}$

\section{Resumo}

Este artigo apresenta uma reflexão sobre a centralidade da ideia de dominação e de poder nos estudos de contato linguístico acerca do estatuto das linguas. Partindo do exemplo do multilinguismo em dois países africanos na pós-colonialidade, o objetivo é questionar a visão etnocêntrica da supremacia de algumas linguas sobre outras, a qual condiciona certa verticalidade no olhar do linguista ao avaliar a valoração das línguas em contato.

Palavras-chave: Minorias linguísticas. Multilinguismo. Linguas em Contato. 


\section{Introdução}

Neste artigo, pretendo discutir a centralidade da ideia de dominação e de poder nos estudos de contato linguístico acerca do estatuto das línguas no âmbito societal (língua majoritária vs. língua minoritária; língua maiorizada vs. língua minorizada; língua maior vs. língua menor). Parto de uma revisão epistemológica do lugar que a Linguística (que considero uma ciência iminentemente social ${ }^{1}$ ) ocupa como área de estudos muitas vezes comprometida com a visão colonialista e etnocêntrica da supremacia das línguas coloniais em convívio com as línguas autóctones, sobretudo dos continentes africano e americano. Apresentarei como exemplificação o estatuto das línguas em contato na situação de plurilinguismo característica dos países africanos na pós-colonialidade, mais especificamente da Nigéria (na África Ocidental) e de Moçambique (na África Oriental). A seguir, abordarei as ideias de "situação minoritária", proposta pelo linguista valenciano Lluís Vicent Aracil" (1983), e de "língua menor", desenvolvida por Deleuze e Guattari (2002), a fim de problematizá-las, tendo como contraponto algumas contribuições da antropologia sobre língua como um sistema cultural. O objetivo principal é ponderar sobre um olhar condicionado a priori, entre os linguistas, por certa verticalidade na valoração da língua "maior" (majoritária, dominante, superior, hegemônica) e "menor" (minoritária, minorizada, subalterna, inferior). Finalmente, proponho uma reflexão sobre a ideia de domínios considerados "baixos" e "altos", uma vez que tais abordagens versam sobre lugares mais de fixidez do que de mobilidade e tendem a destacar a diferença social como a dimensão mais importante a condicionar a alternância entre as línguas, assim contribuindo para a sua perpetuação, e impedindo a emergência de uma lógica distinta, que pressuponha maior mobilidade e fluxo nas relações de poder, sem o habitual essencialismo com que se vê a assimetria entre as línguas.

\section{Uma transição epistemológica necessária nos estudos de contato linguístico}

Os grandes movimentos migratórios e colonizatórios de povos que abandonam seus países de origem pelas mais 
diversas razões se encontram na base da maioria dos contatos entre grupos étnicos, que, convergindo para um mesmo espaço geográfico, não apenas têm de adaptar-se ao novo meio, mas também efetuar trocas culturais com os demais grupos humanos em contato. Nesse particular, a linguagem talvez seja o elemento de troca que mais sofra modificações, considerando-se a relação estreita que existe entre a estrutura social e o uso da língua pelos falantes. Do amplo e continuado contato entre falantes de línguas diversas, resultam situações diversas de multilinguismo e fenômenos linguísticos dele decorrentes, tais como language shift, code-switching, empréstimos, interferências etc.

Todos esses fenômenos linguísticos são sempre cultural e sócio-historicamente construídos, portanto o estatuto das línguas em contato depende igualmente da natureza das relações sociais que se estabelecem, ao longo do tempo, entre sujeitos sociais e étnicos, seus códigos culturais e sistemas de valores linguísticos, habilidades, portanto, que os capacitam a construir padrões identitários. As identidades linguísticas dos sujeitos, assim, definem-se sempre em relação a um Outro e não são entidades fixas, mas construções discursivas fluidas, temporárias e historicamente determinadas. Dessa forma, pesquisar sobre identidades etnolinguísticas envolve investigar qual o significado das línguas para os grupos que as usam, que implicações elas têm em suas práticas cotidianas, o que esses grupos pensam e como eles se sentem em relação a elas.

Quando no panorama do contato linguístico há a dominação de um povo sobre o outro, a exemplo dos processos de colonização da América e da África, a situação de multilinguismo gera conflitos. Se os colonizadores, conquistadores exógenos, detentores do poder político, militar e econômico, delimitam artificialmente para o Estado uma região que abrange territórios de diversos povos e línguas, haverá uma relação de subordinação das línguas e supressão de direitos linguísticos.

De uma perspectiva cultural e política, a reunião de diversos grupos etnolinguísticos dentro de um só Estado leva à tensão sociopolítica e grupal, a prejuízos e legislações injustas, que tentam proteger a maioria e fazer a minoria vulnerável. A pressão da minoria pela maioria, os grupos étnicos majoritários obliterando a existência das minorias até a total 
3 "The sphere of knowledge is critical since controlling knowledge means to control subjectivities. $\mathrm{D}$ e c o lo n i z i n g epistemology is necessary to release sensing and thinking from the prison house of aesthetics and philosophy." (MIGNOLO, 2010).

${ }^{4}$ Sobre o assunto, conferir FANON, 1968, WA THIONG'O, 1986; SAID, 2007; BHABHA, 1994; MUFWENE, 2002; MIGNOLO, 2003 E 2010; SANTOS; MENESES, 2010; SANTOS, 2004, 2006 e 2011; RAMOSE, 2011.

${ }^{5}$ Para uma crítica à ausência do componente social na linguística, conferir CAMERON, 1990. assimilação, pressões para a sobrevivência individual e do grupo foram outras das consequências dos novos estados criados pelos colonialistas. (OBENG; ECHU, 2004, p. 10).

O fim do colonialismo histórico (com a independência da maioria das colônias americanas no séc. XIX e africanas no séc. $X X)$ enquanto relação política não necessariamente acarretou o fim do colonialismo enquanto relação social, enquanto mentalidade e forma de sociabilidade autoritária e discriminatória. Nesse contexto, "a esfera do conhecimento torna-se fundamental, uma vez que controlar conhecimento significa controlar subjetividades. A descolonização epistemológica é, portanto, necessária para a liberdade do sentido e para um pensamento fora da prisão da estética e da filosofia"3 (MIGNOLO, 2010). A perspectiva pós-colonial parte da ideia de que, a partir das margens ou das periferias, as estruturas de poder e de saber são mais visíveis. Daí o interesse dessa perspectiva pela geopolítica do conhecimento, ou seja, por problematizar quem produz o conhecimento, em que contexto o produz e para quem o produz ${ }^{4}$. O sociólogo Boaventura de Souza Santos resume da seguinte maneira essa virada epistemológica:

Proponho como orientação epistemológica, política e cultural, que nos desfamiliarizemos do Norte imperial e que aprendamos com o Sul. Mas advirto que o Sul é, ele próprio, um produto do império e, por isso, a aprendizagem com o Sul exige igualmente a desfamiliarização em relação ao Sul imperial, ou seja, em relação a tudo que no Sul é resultado da relação colonial capitalista. Assim, só se aprende com o Sul na medida em que se concebe este como resistência à dominação do Norte e se busca nele o que não foi totalmente desconfigurado ou destruído por essa dominação. (SANTOS, 2004, p. 17-18)

No que se refere à ciência da linguagem, é necessário que ela incorpore ao estudo do contato entre línguas aspectos socioidentitários, suprindo uma lacuna nos estudos sobre a língua como prática social ${ }^{5}$. Para estudar-se uma situação de contato linguístico entre línguas minoritárias e uma língua oficial majoritária, por exemplo, tal revisão epistemológica é relevante na medida em que a História, o Direito, a Filosofia, as Ciências Sociais - entre elas, a Linguística - estiveram, muitas vezes, comprometidas com a visão colonialista e etnocêntrica da supremacia das línguas ex-coloniais em convívio com 
${ }^{6}$ Conferir os trabalhos de BAMGBOSE, 1993; MAZRUI; MAZRUI, 1998 ; O B ENG; ADEGBIJA， 1999; MUFWENE, 2002.

${ }^{7}$ Projeto internacional, desenvolvido entre 1999 e 2002 por Boaventura de Sousa Santos e mais sessenta investigadores de seis países (Âfrica do Sul, Brasil, Colômbia, Índia, Moçambique e Portugal), que propõe a descolonialidade dos seres e dos conhecimentos, a partir de um movimento contra-hegemônico e de um cosmopolitismo marginal e subalterno que leva em conta a diversidad e epistemológica do mundo, para além do paradigma científico do Norte global.

${ }^{8}$ Termo usado por Marshall Sahlins (2004, p. 11), mas cunhado por Jaqueline Mraz em um artigo não publicado da autora. as línguas autóctones. Abundam exemplos de colonização linguística e de juízos de valor sobre a "inferioridade" das línguas nativas americanas e africanas em exemplos que percorrem os séculos ${ }^{6}$. Como nos lembram os teóricos da pós-colonialidade, o cânone epistemológico da modernidade se engendrou por meio de processos de "marginalização, supressão e subversão de epistemologias, tradições culturais e políticas alternativas em relação às que foram nele incluídas" (SANTOS, 2011, p. 17).

Nessa conjuntura, nasceu um esforço coletivo para desenvolver uma epistemologia do $\mathrm{Sul}^{7}$, a qual engloba uma "ecologia de saberes" e um cosmopolitismo subalterno que se manifesta em um "vasto conjunto de redes, iniciativas, organizações e movimentos que lutam contra a exclusão econômica, social, política e cultural gerada pela mais recente encarnação do capitalismo global, conhecido como globalização neoliberal" (SANTOS, 2011, p. 51). Uma série de conceitos e termos surgiu nas áreas denominadas "afterlogical studies"8 (que reúnem tendências atuais de estudos pós-estruturalistas, pósmodernistas, pós-coloniais, estudos culturais e semelhantes) e vieram ao encontro desse movimento: pensamento de borda, geopolitica do conhecimento, transmodernidade, transnacionalidade, pluridiversidade, hibridismo cultural, etc. Como diria o antropólogo norte-americano, Clifford Geertz, "num mundo estilhaçado, devemos examinar os estilhaços" (GEERTZ, 2001, p. 193). E a teoria social, em particular a antropologia cultural, fê-lo desmontando conceitos outrora totalizantes sobre a semelhança e diferença entre os povos, sociedades, Estados e culturas: tradição, identidade, religião, ideologia, valores, nação, povo:

Precisamos é de modos de pensar que sejam receptivos
às particularidades, às individualidades, às estranhezas,
descontinuidades, contrastes e singularidades, receptivos
ao que Charles Taylor chamou de "diversidade profunda",
uma pluralidade de maneiras de fazer parte e de ser, e que
possam extrair deles - dela - um sentimento de vinculação,
de uma vinculação que não é abrangente nem uniforme,
primordial nem imutável, mas que, apesar disso, é real.
(GEERTZ, 2001, p. 193)

Felizmente, a transição epistemológica pela qual passamos contemporaneamente propicia que emerjam abordagens teóricas mais voltadas para a especificidade, a diferença e a 
Esse movimento decorre da fundamental Conferência de Bandung, em 1955, quando 29 países (15 descolonizados e 14 ainda dependentes) estabelecem os "Dez princípios de Bandung", entre os quais estão o respeito pela soberania e integridade territorial dos Estados; a não utilização de dispositivos de defesa que sirvam aos interesses particulares das grandes potências; a não utilização da força contra a independência dos países; a regulamentação dos conflitos por meios pacíficos etc.

10 Disponível em: < ht t p : / / w w w ethnologue.com $>$. Acesso em: $5 \mathrm{de}$ dezembro de 2016. Nos países africanos as línguas autóctones (subdivididas em dezenas de dialetos) são muito numerosas. A Tanzânia, por exemplo, tem 22.400 milhões de habitantes e 113 línguas, Angola tem 8.700 milhões e 42 línguas, Moçambique tem 19.440 milhões e 24 línguas, a Nigéria tem 95.190 milhões de habitantes e 400 línguas.

11 Política em que a língua oficial é exógena.

12 Diretor do Centro de Estudos Avançados da Sociedade Africana (CASAS) em Cape Town, África do Sul, o qual desenvolve um Projeto de Harmonização de Línguas Africanas (PRAH, 2011). integridade cultural de povos marginais ou periféricos em relação à história e ao imperialismo ocidental (SAHLINS, 2004, p. 10-11), bem como permite deslocar nossa percepção sobre a exclusão social e as relações de poder desiguais sobre as quais ela se constituiu. Nesse sentido, a luta anticolonial das nações africanas, subsequente ao movimento que se chamou "afro-asiatismo" ${ }^{9}$ nos anos 60/70 foi um grande divisor de águas nas ciências sociais e nas humanidades, pois suscitou um redirecionamento do olhar eurocêntrico para a Ásia, a África e a América (e também para a contribuição intelectual periférica desses lugares para o mundo).

\section{Um exemplo: o plurilinguismo característico do continente africano}

A África conserva na atualidade 2.146 das 7.105 línguas que existem no mundo ${ }^{10}$, divididas em 55 países, entre os quais 34 têm políticas linguísticas exoglóssicas ${ }^{11}$ (BOKAMBA, 2011). O multilinguismo caracteriza as nações africanas, e muitos de seus falantes se movem entre as ideias de dominarem uma língua ex-colonial, unificadora de um Estado-nação acima de fronteiras étnicas e regionais, e, por outro lado, de conservarem interesses e objetivos vinculados ao uso vernacular das línguas autóctones. Segundo o antropólogo sul-africano Kwesi Kwaa $\operatorname{Prah}^{12}$, o fato de as fronteiras coloniais dividirem falantes de $90 \%$ das línguas africanas em diferentes territórios e, por conseguinte, imporem diferentes identidades estatais a um povo que desde tempos imemoriais sempre foi o mesmo etnoculturalmente é um dos problemas mais embaraçosos da África (PRAH, 2011, p. 273). A questão diz respeito não apenas às estruturas governamentais e às línguas separadas pelas fronteiras arbitrariamente demarcadas. Posições conflitantes sobre tal problema estão relacionadas às funções sociais e pragmáticas das línguas, a relações de poder entre centro e periferia, modernidade e tradição, identidade étnica, perda de valores ancestrais, elitização social, prejuízo pela segregação de grupos minoritários, alienação cultural, insucesso escolar, educação bilíngue para as minorias.

A experiência de séculos de dominação criou feições particulares nas identidades das pessoas e culturas que constituem os países que foram dominados pelas potências 
europeias. Walter Mignolo (2010) chama de "ferida colonial" a dificuldade por que passa o indivíduo colonizado para estabelecer uma identidade que se vê entre matrizes culturais diferentes. Esse sentimento permeia a maioria das questõeschave de desenvolvimento na África pós-colonial, onde, mesmo depois de meio século de descolonização, a estrutura colonial ainda se faz sentir nos sistemas políticos, econômicos, e também nos sistemas educacionais, que permanecem em sua maioria eurocêntricos (anglófonos, francófonos e lusófonos), em um quadro de altos índices de analfabetismo, alta taxa de evasão em todos os níveis de ensino, difícil acesso à universidade e dificuldade de colocação profissional dos diplomados.

Há tipos distintos de situação multilinguística em cada país da África, os quais foram classificados da seguinte maneira por Abdulaziz (2003, p.108): primeiramente, estão aqueles estados onde a maioria da população fala uma língua africana, seja sua língua materna ou uma língua franca, como Botswana, Ruanda, Etiópia, Tanzânia e Senegal. Em situação semelhante, estão Burkina Faso, Gana e Zimbábue, nos quais existe uma língua africana predominante, mas existem muitas outras minorias linguísticas significativas. Outro cenário é o dos países que têm vários idiomas africanos dominantes e o consequente problema de competição e rivalidade entre eles, como a Nigéria e o Congo. E por último, os países onde prevalece um idioma europeu e nenhuma língua africana é oficial, como a Costa do Marfim, Camarões e Moçambique.

A Nigéria é o país africano com um maior nível de multilinguismo, com mais de 500 línguas faladas, três línguas oficiais (hausa, yoruba, ibo) desde a Constituição Federal de 1999 e uma língua cooficial, o inglês (ADEGBIJA, 2007). As línguas oficiais são usadas no sistema educacional e na administração pública, enquanto na assembleia de deputados e nos domínios oficiais usa-se apenas a língua inglesa. Não obstante seja usado nas esferas de mais prestígio, o inglês não tem maior representatividade em termos numéricos do que as outras línguas. Tanto o hausa como o inglês são línguas faladas por $20 \%$ da população, aproximadamente. O yoruba representa $18 \%$ e o ibo, $15 \%$.

Como em muitos outros países africanos, a grande presença de minorias linguísticas na Nigéria gera conflitos entre os grupos étnicos devido à concorrência entre os 
dialetos para sua sobrevivência. Adegbija (2007, p.190) afirma que, em virtude de tais problemas, nos censos se evitam perguntas acerca das línguas faladas pela população, o que ocasiona dificuldades para medir o número de línguas e de seus falantes na Nigéria. Nenhuma das três línguas oficiais tem plena aceitação nacional. Há, no entanto, uma língua nigeriana que preenche os quesitos necessários de língua pátria: o pidgin English, ou naija, língua materna de cerca de 30 milhões de pessoas (mais do que qualquer das três majoritárias) amplamente utilizada como língua veicular entre as classes mais pobres dos centros urbanos e dos habitantes da zona rural. A barreira para sua utilização é o preconceito que o naija sofre das classes dominantes, pois é visto como um inglês corrompido e, portanto, descartado em todas as esferas de poder (FARACLAS, 1988).

Em Moçambique, a única língua oficial é o português, ao lado de 24 línguas autóctones e outras línguas estrangeiras, como o inglês e as línguas de origem asiática, todas com papéis e funções distintas. Embora tenha havido nas décadas de 1980 e 1990 algumas tentativas de planificação linguística para contemplar a diversidade linguística do país, ela nunca foi empreendida de fato. Sem uma política linguística explícita a favor das línguas bantu moçambicanas e com a centralização em torno do português, as pessoas se organizam de forma a gerir seus repertórios linguísticos na diversidade, movendose por interesses variados, não sistemáticos, seguindo a característica plurilíngue e multi-identitária.

Ao pesquisar sobre a questão linguística em Moçambique, Firmino (2002, p. 20) apresenta dois posicionamentos sobre a coexistência - assimétrica e competitiva - entre as línguas excoloniais (usadas em domínios secundários, como governo, administração, sistema judicial, educação, ciência, tecnologia) e as línguas africanas autóctones (usadas em domínios primários, como vida social, família, amigos, mercados). Por um lado, há a concepção de que as línguas coloniais afastariam os africanos de sua identidade autêntica, aumentando a dependência em relação ao mundo ocidental - posição abolicionista. Por outro, há a defesa de que as línguas coloniais promovem a renacionalização dos países pós-coloniais conjuntamente com as línguas autóctones - posição adaptacionista. Muitas vezes, tal questão é posta em termos socioeconômicos: caso a 
unificação não seja contemplada, e, sim, a heterogeneidade, haverá um problema político e econômico; ou seja, uma nação que não se organiza em torno da unidade linguística não pode se unir em torno da inteligibilidade mútua. Essa ideia se baseia na concepção da língua como um elemento simbólico essencial para o sentimento nacionalista na formação dos Estados-nação depois das lutas de independência dos anos 1970. Contudo, além desse ideal de unidade linguística, deve-se considerar o fato de que quem dominava a língua da administração nas nações recém-independentes era uma restrita elite política e intelectual.

Prah atribui o poder cultural das elites africanas hoje ao fato de falarem as línguas ex-coloniais: "recompensas sociais e mobilidade social vertical são, em grande medida, conseguidos na África neocolonial (tal como aconteceu na África colonial) através da língua colonial" (2011, p. 271). Para Firmino, o uso da língua colonial é um exemplo de "fechamento da elite", estratégia através da qual a política linguística é usada pelos que estão no poder para mantê-lo, bem como seus privilégios:

A oficialização das línguas ex-coloniais em muitos países africanos, que é frequentemente acompanhada por uma falta de medidas para permitir, à maioria dos cidadãos, o acesso a elas ou para promover as línguas nativas, é, até certo ponto, um exemplo dessa estratégia. (FIRMINO, 2002, p. 72).

Da mesma forma que ocorre com o naija, o iorubá, o ibo e o hausa, as línguas autóctones moçambicanas não têm nada de intrinsecamente "minoritário", sequer em termos de números de falantes. Porém, como a maior parte das línguas africanas, viveram um processo paulatino e sistemático de minorização política, socioeconômica e cultural que interfere negativamente na vida de seus usuários, em sua autoestima, em seus direitos básicos à cidadania.

Alguns linguistas e estudiosos têm defendido a complementariedade na diversidade como um caminho para as políticas linguísticas na África. Em outras palavras, não se trataria de escolher entre a língua de colonização e as línguas autóctones, mas de reconhecer a complexidade linguística que caracteriza tais países, a qual prevê o uso tanto das línguas excoloniais, que garantem o acesso a bens culturais e inserção no 
mercado de trabalho, quanto das línguas nativas, que têm uma função identitária, étnica, de lealdade à família e aos valores tradicionais. Não seria uma questão de minimizar diferenças culturais e linguísticas entre os falantes, mas de reconhecê-las como traços da estrutura política e econômica da sociedade, que justamente permitem o dinamismo da disputa pelos recursos sociais.

\section{A situação minoritária e a língua menor}

Lluís Vicent Aracil, proemiente sociolinguista valenciano, define a "situação minoritária" como decorrente de mudanças sociolinguísticas trazidas pela modernização, as quais forçam algumas comunidades de línguas minoritárias a tornaremse bilíngues unilateralmente (por exemplo, em Moçambique, a maior parte dos falantes de xirhonga são também falantes de português, mas nem todos os falantes de português são também falantes de xirhonga). Aracil argumenta que essa questão do bilinguismo unilateral envolve noções intuitivas dificilmente apreensíveis, já que a situação minoritária consiste em uma história vivida por pessoas que constroem sentidos para suas vidas em um lugar intermediário, de "interposição", e compreender esse aspecto da questão requer recursos de uma sociologia fenomenológica, mais que de um aparato matemático.

O problema da investigação sociolinguística no contato de línguas seria, então, compreender as dinâmicas e os poderes implicados nessa relação que está "entre". Por interposição, Aracil entende que o típico da situação de minoria é o fato de que (quase) todas as relações entre a comunidade linguística de uma língua $X$ e o resto da humanidade passa pelo idioma Y. Assim, a relação entre língua majoritária e minoritária seria uma relação de intermediação de sentidos entre mundos culturais diversos.

Cumpre aqui distinguir língua minoritária de língua minorizada, conceito criado pelo próprio Aracil em 1983. Língua minoritária refere-se à demografia relativa de um idioma, às dimensões numéricas de uma comunidade linguística. Pode haver línguas minoritárias com estatuto de oficiais ou não. Lingua minorizada é qualquer língua que, dividindo o espaço geográfico com outra ou outras, tem alguns de seus usos restringidos. Portanto, a minorização (termo usado em profusão na literatura 
${ }^{13}$ (a) Normas de uso social restrictivas en relación a la lengua propia -es decir, que dicha lengua no puede usarse en determinados ámbitos de usofrente a las normas de uso expansivas características de la lengua dominante. (b) Bilinguización unilateral de los miembros de dicha comunidad, esto es: los hablantes de la lengua minorizada tienen en su repertorio la lengua propia y la dominante, mientras que los hablantes de esta última tienden a ser monolingues. (c) Como consecuencia de la situación anterior, la comunidad linguística minorizada se convierte en un subconjunto de la dominante. Los miembros de la comunidad minorizada tienden a presentarse como parte de la comunidad dominante, y así son percibidos por el resto del mundo. sociolinguística hispânica sobre a situação do catalão, galego, valenciano etc) não depende do número de falantes, mas do status de que goza a língua. Também pode acontecer de haver línguas majoritárias minorizadas, pois, embora usadas pela maioria das respectivas populações, não gozam de estatuto de oficialidade, por exemplo. É o caso das línguas autóctones de muitos países africanos em relação às línguas ex-coloniais.

Para Guillem Calaforra (2003), uma comunidade linguística é minorizada quando apresenta principalmente três características: (a) normas sociais restritivas em relação ao próprio uso - isto é, essa língua não se pode usar em determinados âmbitos - contra as normas de amplo uso características da língua dominante; (b) bilinguismo unilateral dos membros dessa comunidade, isto é, falantes da língua minoritária têm em seu repertório a língua própria e a dominante, enquanto que os falantes dessa última tendem a ser falantes monolíngues; (c) como resultado da situação acima, a comunidade linguística minorizada se torna um subconjunto da dominante. Os membros da comunidade minorizada tendem a apresentar-se como parte da comunidade dominante, e assim são percebidos pelo resto do mundo. (CALAFORRA, 2003, p. 2)

Conquanto descreva com certa neutralidade as características acima, quando explica a relação entre minorização e poder, Calaforra transparece um forte tom ideológico ao considerar a minorização como "impotência linguística":

A língua não minorizada - ou língua vigente - é um dos elementos-chave de integração e exclusão social: a posição do sujeito na estrutura social se vê parcialmente determinada pelo seu grau de domínio da língua corrente. Nas sociedades modernas, esse nível de competência linguística determina promoção ou exclusão do sujeito no sistema de produção. [...] O uso da língua minoritária é reduzido a ser um "direito" de seus falantes, em vez de servir às funções sociais de uma língua existente. No melhor dos casos, a estrutura da situação de minoria permite a utilização dessa linguagem, mas impede a possibilidade de ordenar tais usos linguísticos. O uso da língua minoritária não dá acesso a maior capital simbólico e material, e muitas vezes inibe a capacidade de obtê-los. Por não desempenhar as funções de discriminação e integração nessas línguas, o poder de regular o uso linguístico (isto é, de ordenar e impedir) é reservado à língua dominante. (CALAFORRA, 2003, p. 4, grifos nossos) ${ }^{13}$ 
Neste ponto, parece-me importante avaliar que, nos trabalhos sobre línguas minorizadas em geral, permanecem as dicotomias que pressupõem uma verticalidade de poderes: língua majoritária é associada à dominação, e língua minorizada, à subordinação. Inevitavelmente, transparece certa "tragicidade" ou "catastrofismo" por trás de certos discursos em defesa das línguas minoritárias. Com frequência, subjazem a eles categorias ligadas a uma teoria social do "constrangimento", da "restrição", do "condicionamento", na qual o comportamento humano é talhado, moldado, ordenado e definido por forças sociais e culturais externas: pela cultura, pela estrutura mental, pelo capitalismo. Não que tudo isso não tenha importância, mas uma teoria social que descuide da agência humana e das práticas sociais é problemática (ORTNER, 2006, p.2). Talvez sejam necessários um deslocamento ou uma inversão não apenas da centralidade da dominação na explicação que damos ao estatuto das línguas, mas da falta de parcialidade e isenção que, nós, os próprios linguistas, temos a respeito da questão dos pesos e valores atribuídos a elas.

O estabelecimento de uma variedade de prestígio entre tantas (ou de uma norma ou de uma língua oficial) é antes de tudo uma decisão política de intervenção sobre a heterogeneidade linguística de uma população, decisão que contribui para o estatuto das línguas, para a percepção que delas têm os falantes e, por fim, para a sua identidade linguística (incorporação de um habitus, conforme Bourdieu, 1998 e 2004), e não o contrário, como está subentendido em muitos discursos a esse respeito. Segundo Monteagudo (2012, p. 39), “a base para um código normativo padrão é uma variedade linguística associada a usos e usuários privilegiados que, além disso, costuma ser adotada por esse grupo de status como emblema distintivo de sua posição hegemônica". Para o autor, essa variedade que constitui o axioleto tem caráter "supradialetal", ou melhor "transletal" e é vedada "mais ou menos severamente" aos grupos sociais "inferiores". Como se vê, não é possível excluir da discussão sobre a relação de hierarquia das línguas e dos conflitos entre variedades de língua ou de línguas entre si as dimensões políticas e sociais. No entanto, essa atribuição de pesos às línguas em termos de 
dominação é vista em geral como mantenedora do status quo linguístico. Como aponta Lagares (2015)

Produz-se assim uma espécie de circularidade entre reconhecimento oficial e desenvolvimento funcional: a intervenção política sobre a língua oficial, o planejamento do seu "corpus", a elaboração de instrumentos linguísticos para ela (ortografia, gramáticas e dicionários), faz crescer o seu reconhecimento simbólico, e ao mesmo tempo esse poder simbólico adquirido é justificado precisamente em nome do seu desenvolvimento linguístico e funcional, por possuir a língua oficial (e só ela) esses instrumentos que a fazem ser socialmente mais útil do que as outras. (LAGARES, 2015, p. 120)

Essa situação nos remete a Bourdieu ([1983] 2004), para quem a ordem arbitrária se torna legítima através da sustentação da crença de que ela é natural ou inevitável. (O conceito de "hegemonia" de Gramsci, ou de "Aparelho Institucional do Estado", de Althusser, apoiam essa mesma visão.) Sobre isso, continua Lagares:

Ao converter as consequências (a desigualdade social, de fato, entre as línguas) em causas, o liberalismo linguístico realiza uma inversão, oferece uma visão invertida da realidade, própria da ideologia (tal e como é entendida pelo Marxismo). Naturaliza as desigualdades e o lugar social que ocupam as línguas (e, portanto, os falantes) e, no extremo, acaba incorrendo em um certo "fatalismo". Essa naturalização da desigualdade linguística pode ser associada à noção de "hegemonia" empregada por Gramsci, que a entende como uma espécie de "consentimento espontâneo" do conjunto da sociedade em relação à direção intelectual e moral dos grupos dominantes; esse consentimento alicerça a legitimidade do poder e produz as certezas do senso comum que se impõem a todos. (LAGARES, 2015, p. 121)

Questionando o conceito clássico de diglossia conforme Ferguson, para quem ela representava uma repartição funcional harmoniosa de usos, linguistas europeus implicados em situações diglóssicas (chamados de "linguistas nativos", por Calvet, 2007, p. 33) ${ }^{14}$, lembram que não se pode excluir

14 Particularmente Robert Lafont, no lado dos occitanos; LambertFélix Prudent, no lado dos crioulófonos e Lluis Aracil, no lado dos catalães. (CALVET, 2007, p. 33) da discussão clássica sobre variedades altas e baixas uma dimensão conflitiva de disputa por recursos sociais, que não só justifica a posteriori as suas consequências, como explica $a$ priori o seu surgimento e consolidação. Calvet lembra que o fato de a Catalunha ter recuperado sua autonomia e contado 
com possibilidades de intervenção política e linguística (Llei de Normalitzacio Linguistica a Catalunya, 23 de abril de 1983) facilitou o deslocamento progressivo de tais assuntos teóricos para a militância. E a militância "ecológica" das línguas, que luta contra o seu desaparecimento e extinção, pode muitas vezes implicar o reverso da moeda do discurso da dominação.

A questão, muitas vezes, apresenta-se como ontológica, mas, na verdade, é axiológica. O que os falantes pensam sobre uma variedade linguística é um juízo valorativo e diz respeito a uma teoria dos valores (axió = estimar, em grego; axiologia $=$ teoria dos valores; onto = ser, em grego; ontologia = teoria do ser). O juízo axiológico acontece quando valoramos as coisas ou as condutas na ordem social, que serão boas ou más segundo as virtudes ou os vícios que contêm. Quando essas características são acidentais e não essenciais (essencial é o ser humano ser dotado de linguagem; acidental é a linguagem expressar-se em uma língua minorizada, por exemplo), não podem ser consideradas como intrínsecas àquela variedade de língua, mas sim intrínsecas à relação que existe entre a língua e os julgamentos que os falantes lhe atribuem.

Assim, o uso da língua é uma escolha individual, expressa no corpo dos sujeitos (por meio de decisões, ações, atitudes, afetos, desejos, explicações), mas essa individualidade é poderosamente mediada pela história e produto da cultura em que o indivíduo está inserido. Nosso comportamento linguístico está inseparavelmente ligado aos valores que estabelecemos para ele em sociedade (ao que é considerado bom e belo e certo em determinada cultura). Porém, não ao que é bom e belo e certo em termos de uma "natureza comum inerente a todos e a cada um dos seres", e sim ao que foi criado por um padrão dominante de valores sociais que são tomados como referência para o que é bom e belo e certo. Redirecionar esse pensamento na Linguística talvez aponte rumos promissores para entendermos por que persistem as variedades linguísticas de "desprestígio". Afinal, quem é que determina (e desde que lugar) o que é "prestígio"?

Se a língua minorizada não é definida pelo número menor em termos quantitativos, mas pelo afastamento, pela distância do axioma dominante em um nível societal, isso não significa que, enquanto devir e potência, ela não aja nesse mesmo espaço societal de forma rizomática, dispersa, fugidia, 
fractal. Por ser minoria, não pode ser categorizada numa generalidade definitória, classificatória e normatizadora. Isso não significa, absolutamente, que a minoria não tenha poder. É como se o espaço de exclusão fosse ingovernável, e isso está no nível da potência, do devir, da agência. Se está no nível do devir e da agência, justamente por não ser apreensível e categorizável é que sempre pode reinventar-se, estar à margem, agir à margem. Como reflete Deleuze:

No Ocidente, o padrão de qualquer maneira é homem, adulto, macho, cidadão [...] Portanto irá obter a maioria aquele que, em determinado momento, realizar este padrão. Ou seja, a imagem sensata de um homem adulto, macho, cidadão. Mas posso dizer que a maioria nunca é ninguém. É um padrão vazio. Muitas pessoas se reconhecem neste padrão vazio. Mas, em si, o padrão é vazio. As mulheres vão contar e intervir nessa maioria, ou em minorias secundárias a partir de seu grupo, relacionados a esse padrão. Mas ao lado disso, o que há? Há todos os devires que são minoria. As mulheres não adquirem o ser mulher por natureza. Elas têm um devir mulher. Se elas têm um devir mulher os homens também têm. Falamos do devir animal. As crianças também têm um devir criança. Não são crianças por natureza. Todos os devires são minoritários. Só os homens não têm devir homem. Não, pois é um padrão majoritário. É vazio. O homem macho, adulto, não tem devir. Pode devir mulher e vira minoria. A esquerda é um conjunto de processos de devir minoritário. Eu afirmo: a maioria é ninguém e a minoria é todo mundo. Ser de esquerda é isso: saber que a minoria é todo mundo e que é aí que acontece o fenômeno do devir. ${ }^{15}$

Na ponta do rizoma, do devir, a minoria só enxerga a totalidade, e não vê nem sente que aquilo que marca sua identidade, e lhe pertence - é um devir minoritário. Esse minoritário só passa a ser minorizado quando o falante é excluído, ou oprimido por ter essa identidade. A partir daí, a atitude de manutenção linguística pode ser uma ação consciente, ou não, pode ser recusa, permanência, teimosia, lealdade, eficácia, reciprocidade, necessidade, interesse, cooperação, solidariedade. Assim, a língua menor é a saída

15 Entrevista com Gilles Deleuze: "O que é ser de esquerda?". Disponível em: <https://www. y o u t u b e.com / watch $? \mathrm{v}=\mathrm{AF} 9 \mathrm{EUm}$ kkqx0>. Acesso em: 16 de dezembro de 2016. rizomática, é o escoar da identidade que se reconstrói a cada interação; é a fuga da estrutura sem sair da estrutura.

Ao usarem o adjetivo "menor" para qualificar o uso e a função de uma língua ou de uma literatura, Deleuze e Guattari afirmam: "Uma literatura menor não pertence a 
uma língua menor, mas, antes, à língua que uma minoria constrói numa língua maior. E a primeira característica é que a língua, de qualquer modo, é afetada por um forte coeficiente de desterritorialização." (DELEUZE; GUATTARI, 2002, p. 38, grifos nossos). O que significa desterritorialização?

O caráter minoritário de uma língua estende-se às condições de uma prática minoritária e revolucionária em toda língua. "Menor" é aquela prática que assume sua marginalidade em relação aos papéis representativos e ideológicos da língua e que aceita a desterritorialização (enquanto exílio) no interior das práticas comunicativas majoritárias, sendo estrangeiro na própria língua, envergonhando-se, gaguejando, deixando emergir o sotaque e o estranhamento de quem fala fora do lugar e ainda assim aceita e assume o não-lugar como seu deserto, na impossibilidade de uma origem. Assim, para assumir uma prática menor, ou "devir minoria", basta "encontrar seu próprio ponto de subdesenvolvimento, seu próprio patoá, seu próprio terceiro mundo, seu próprio deserto" (DELEUZE; GUATTARI, 2002, p. 28-29)

A maioria dos moçambicanos não domina bem o português, a língua oficial do Estado. Tampouco o Estado oficializou as duas dezenas de línguas autóctones da sua Nação. Assim, a desterritorialização das línguas moçambicanas (entre elas o português, inclusive) demostra uma ruptura tanto do compromisso nacional com o estofo de suas línguas maternas e da identidade orgânica que naturalmente representam, quanto com a língua que acolheu como oficial e que facilita a mobilidade social e o prestígio social daí resultante. A impossibilidade de expressar-se oficialmente em outras maneiras que não a língua oficial é para os moçambicanos o sentimento de uma distância em relação à territorialidade primitiva das línguas bantu. A impossibilidade de expressar-se bem e totalmente em português moçambicano é a desterritorialização da própria população moçambicana minorizada em suas línguas (no sentido de minorização de Aracil), que fala outra língua que não a das massas, uma língua exógena.

Em Moçambique conjecturo uma situação em que, por um lado, muitos cidadãos irão conduzir suas vidas ou numa (uma ou mais) língua autóctone ou em Português. Alguns moçambicanos, no entanto, irão usar uma língua autóctone e o Português. Nenhuma das línguas autóctones será alargada para os moçambicanos num futuro próximo. Assim, uma língua autóctone largamente falada como língua 
nacional não pode emergir, nem o Português vai se tornar instrumento de comunicação para todos os moçambicanos do país inteiro, apesar de haver condições sociais e esforços do Estado para promover a sua expansão para um maior número de cidadãos. (FIRMINO, 2002, p. 272-273)

A segunda característica das literaturas e das línguas menores é que nelas tudo é político. Nas grandes literaturas, o foco é o indivíduo, e o social é cenário, serve de ambiente e de fundo. Na literatura menor, é o contrário: o seu espaço, sendo exíguo, faz com que todas as questões individuais estejam imediatamente ligadas à política: "A questão individual, ampliada ao microscópio, torna-se muito mais necessária, indispensável, porque uma outra história agita-se no seu interior." (DELEUZE; GUATTARI, [1977] 2002, p.39). O que nas grandes literaturas e nas línguas majoritárias é basilar e subjacente, aqui passa a ser exposto à luz do dia, passa a ser uma questão central e crucial. Assim, o evento/performance multilíngue nunca se separa dos cenários estatal, burocrático, administrativo, jurídico, educacional, econômico, político que lhe atribuem e destinam valores sociais. Ainda que seja analisada a competência comunicativa individual, na questão linguística africana, a identidade etnolinguística sempre alcança os limites dos âmbitos citados acima, que, como referência, nunca se separam dos eventos de fala. Assim, fazer uso de uma língua menor em um contexto em que ela é minorizada, em que seus falantes - tendo-a como língua materna - não veem seu registro e uso em lugares como o tribunal, o hospital, a escola, a administração pública é um gesto político que está para além do gesto identitário. $\mathrm{O}$ multilinguismo está. O plurilinguismo age.

A atitude política no uso das línguas está em "fazer", e não em "ser". Não há uma consciência ideológica de ser contra nada, de lutar, de resistir... A atitude que posso perceber é que a manutenção das línguas é resultado de suprir a identidade e a ideologia de uma consciência nacional muitas vezes inativa e sempre em vias de desagregação e no cumprimento de tarefas coletivas na falta de uma ingerência pelo Estado. É por essa desarticulação entre a consciência coletiva da Nação e a negação por parte do Estado que os falantes se tornam positivamente encarregados do papel político, isto é, ao exprimir, por meio da afirmação das línguas em atos identitários na comunidade imaginada, potencialmente, o devir minoritário. 
A terceira característica da língua menor é que nela tudo toma um valor coletivo (DELEUZE; GUATTARI, [1977] 2002, p. 40). As condições não são dadas numa enunciação individuada, separável da enunciação coletiva. A língua menor seria assim uma língua de grupo, ou de gueto. Não se assume uma língua dessas sem estar comprometido com a sua coletividade e a sua luta.

O campo político contaminou o enunciado todo. Mas, sobretudo mais ainda, porque a consciência coletiva ou nacional é a maior parte das vezes inativa na vida exterior e continuamente em vias de desagregação. É a literatura que se encontra carregada positivamente desse papel e dessa função de enunciação coletiva e mesmo revolucionária: a literatura é que produz uma solidariedade ativa apesar do ceticismo; e se o escritor está à margem ou à distância da sua frágil comunidade, a situação coloca-o mais à medida de exprimir uma outra comunidade potencial, de forjar os meios de uma outra consciência e de uma outra sensibilidade. (DELEUZE; GUATTARI, [1977] 2002, p. 40).

A "máquina da língua" se torna uma máquina revolucionária, não por razões ideológicas intencionais - o que lhe conferiria o caráter de língua de "resistência" -, mas porque está determinada, nem sempre deliberadamente, a preencher as condições de enunciação coletiva de um povo, o que lhe confere características de "permanência". Assim, o aspecto imediatamente político da literatura menor não tem a ver com seu conteúdo ideológico, mas com sua performance enquanto uma multiplicidade de atos de fala que forma uma máquina expressiva.

E aqui abro um parênteses para a ideia de coletividade no continente africano (ubuntu), que dificulta pensar em um ator social deslocado dessa coletividade. $\mathrm{O}$ agenciamento não está somente no nível do sujeito, individualmente, e sim é concebido sempre com interesse coletivo, pertencimento a algo maior. Logo, a quebra de um padrão de individualidade identitária pode estar por trás dessa ideia de "permanência". Nesse caso, a desterritorialização da língua implica uma via dupla: os africanos in-between, na zona intersticial entre as línguas autóctones e as línguas europeias ex-coloniais. Há algumas saídas possíveis: por exemplo, encher esse idioma colonial de expressão bantu ou iorubá, enriquecê-lo artificialmente, descolonizá-lo, ressignificá-lo. 
Quantos é que vivem hoje com uma língua que não é sua, ou então nem sequer a sua conhecem ou ainda não a conhecem, e conhecem mal a língua maior que são obrigados a utilizar? Problemas dos imigrantes, e sobretudo dos filhos deles. Problema das minorias. Problema de uma literatura menor, mas também de todos nós. Como é que se extrai de sua própria língua uma literatura menor, capaz de pensar a linguagem e fazê-la tecer conforme uma linha revolucionária sóbria? Como definir o nômade, o imigrante e o cigano da sua própria língua? Kafka dizia: roubar a criança no berço, dançar na corda bamba. (DELEUZE; GUATTARI, [1977] 2002, p. 43)

Assim interpreto "menor", no pensamento de Deleuze e Guattari e no caso deste artigo, como característico dessa língua desterritorializada, do individual ligado ao imediato político, e do agenciamento coletivo de enunciação com vistas à permanência. Melhor seria dizer que "menor" não qualifica certas línguas, mas as condições revolucionárias de permanência dessas línguas no seio daquela a que se chama oficial, ou majoritária. Assumir o seu próprio "menor, o seu próprio subdesenvolvimento, o seu patoá, o seu próprio terceiro mundo, o seu próprio deserto". O que é marginal, periférico etc.? Qual é o devir de uma língua menor (minorizada)?

Existe uma tensão entre a língua desterritorializada e a reterritorialização. $\mathrm{O}$ espaço entre, a faixa de terra, o meio do caminho, são um território de ninguém; "terra sem lei", em que as pessoas se apropriam dos sentidos e lhes atribuem o valor que desejam. Em uma democracia jovem, em um país de mudanças sociais rápidas, o fluxo, a mobilidade e a flexibilidade, mais do que a estrutura, são o cenário da reterritorialização. Não é o indivíduo o sujeito da enunciação ou do enunciado, mas um circuito de potências e devires dentro do continuum que vai do traço (+bantu) até o traço (+português), do traço (+ioruba) ao traço (+inglês), no seio de um agenciamento necessariamente político e marcadamente múltiplo ou coletivo. Nessa tensão que é dançar na corda bamba, muitas vezes o menor é tão menor, que passa a ser maior.

\section{Estatuto das línguas em contato, mobilidade e fluxo nas relações de poder}

O que propus aqui neste artigo foi olhar para este campo particular - as línguas em contato - desde um tipo de 
enquadramento que pressuponha maior mobilidade e fluxo nas relações de poder, sem o habitual essencialismo com que se vê a assimetria entre as línguas. E para terminar, recorro à antropologia contemporânea e à ideia de língua como um sistema cultural (GEERTZ, 1997, p. 114) que, tanto quanto as artes, a ciência, os modelos econômicos, as religiões, entre outros, é "um corpo organizado de pensamento deliberado" que faz sentido profundo na experiência cultural dos falantes.

Essa compreensão de língua como sistema cultural é muito importante porque permite acordar para dois aspectos. Primeiro, que a língua é um sistema, como a religiosidade ou a família, constituinte da experiência social do falante. Não é um fato externo, um dispositivo ou um mecanismo que alguém tira, muda ou impõe em algum momento determinado da vida de um outro. A língua é constitutiva das relações sociais de um sujeito, mas também é constituída constantemente por elas, não no sentido de ser um veículo de comunicação, mas um forte marcador de identidade e de diferença. Com a língua, como com outros marcadores sociais, os sujeitos ou redes ou grupos sociais estabelecem relações semelhantes: produção, reprodução etc. Isto é, o falante não apenas fala uma língua, disponível e externa a ele; ele é essa maneira linguística, encarna culturalmente uma relação com o sistema simbólico chamado "língua", o conjunto de suas variações, os julgamentos que se atribuem a elas, sua memória, seus limites e possibilidades. $\mathrm{O}$ falante, então, é um sujeito linguístico, no mesmo sentido que pode ser um sujeito de gênero ou um sujeito de raça/cor. Ele é as línguas que usa.

Segundo, lembrar esse fato nos permite acessar o universo das diversidades culturais a partir de um lugar que não o das negatividades. Isto é, entender que as estruturas que dão sentido ao mundo não são as mesmas para todos os grupos humanos, que não existem formas universais de ser, de agir, de sentir, de representar... e de falar. Muito pelo contrário, não só evidenciamos a cada dia uma profusão maior de formas diferentes de ser humano, como damos à diferença um lugar de destaque em nossas análises. Aprendemos que a pluralidade de experiências culturais é um fato muito mais próximo e mais intenso do que imaginávamos. E para descrevêla, ou para dar conta das performances no "contexto nativo da 
atividade linguística", no sentido metodológico, o relativismo deve sempre estar pressuposto:

Trata-se da simples prescrição de que para serem inteligíveis as práticas e ideais de outras pessoas devem ser situados e seu próprio contexto compreendidos como valores posicionais num campo de suas próprias relações culturais, e não apreciados em termos de juízos intelectuais e morais fabricados por nós. O relativismo é a suspensão provisória dos nossos próprios juízos, a fim de situar as práticas em questão na ordem histórica e cultural que as tornou possíveis. (SAHLINS, 2004, p. 22).

O poder, seja entre os atores sociais, seja entre as classes ou instituições, é visto por teóricos como Bourdieu (1998), como sinônimo de dominação e desigualdade, com forte ênfase no poder das estruturas e da hegemonia cultural. Entretanto, deslocando-se a ideia de poder desses lugares (das macroinstituições para as microinterações, ou da hegemonia que produz e conforma, para a contra-hegemonia que resiste e transforma) pode-se perceber, empiricamente e em âmbitos específicos de atuação, uma estratégica zona intersticial onde o falante híbrido mantém sua identidade linguística múltipla. E, se o faz, é porque talvez lhe interessem mais as ações de evadir e de resistir às estruturas hegemônicas do que submeterse ou aceitá-las passivamente. Como explicar em termos de uma "teoria do poder" o estatuto e o valor das línguas na multiplicidade de práticas em seus âmbitos de eficácia?

Finalmente, temos de lembrar que a consideração de alto e baixo, no contexto africano, está inserida em uma arena na qual os falantes se esforçam diariamente por apropriar-se, resistir e ressignificar o sistema ideológico monocultural que impuseram tanto o Estado colonial, como o Estado contemporâneo. O importante aqui é ponderar que, no caso da África, as tradições populares locais, a educação em casa, a curandeira, a música, os ritos, os casamentos e falecimentos, a tradição da oralidade, da culinária, da medicina tradicional etc., nada disso é domínio baixo, do ponto de vista do falante. As categorias e critérios segundo os quais julgamos o que está "acima" e "abaixo" em termos de valores culturais e linguísticos são relativos.

A atitude de permanência e vitalização das línguas minoritárias pode ser uma ação deliberada na esfera de uma escolha política e coletiva de reterritorializar as línguas 
desterritorializadas e construir identidades linguísticas híbridas em meio a essa interculturalidade. Assumir a prática de marginalidade das línguas bantu ou iorubá em relação ao papel ideológico e hegemônico da língua portuguesa e inglesa (para ficar apenas nesses exemplos de Nigéria e Moçambique) e aceitar a desterritorialização de ambas é reterritorializá-las no espaço de fluxo, de intermediação, sendo e vindo-a-ser (no sentido de Ubuntu, que é um gerundivo, ou seja, um nome verbal denotando simultaneamente um estado de ser e de tornar-se), neste não-lugar, um devir minoritário, e encontrando nele alternativas de escoamento, de vazante, fluidez, saída, ressignificando o valor sociossimbólico atribuído às línguas nas últimas décadas.

\section{REFERÊNCIAS}

ABDULAZIZ, M. The History of language policy in Africa with reference to language choice in education. Towards a Multilingual Culture of Education. OUANE, Adama. Hamburgo: UNESCO, 2003.

ARACIL, Lluís Vicent. Sobre la situació minoritária. Dir la realitat. Barcelona: Edicions Països Catalans, p. 171-206, 1983.

ADEGBIJA, E. Language policy and planning in Nigeria. In: KAPLAN, R.; BALDAUF Jr. Language planning and policy Africa, vol. 2. De EE.UU: Multilingual Matters, 2007.

BAMGBOSE, A. Language and the nation: The language question in Sub-saharan Africa. Edinburgh: Edinburgh University Press, 1991.

BOKAMBA, E. G. Ukolonia in African Language Policies and Practices. In: BOKAMBA, E. G.; SHOSTED, R. K.; AYALEW, B. T. (eds). Selected Proceedings of the $40^{\text {th }}$ Annual Conference on African Linguistics: African Languages and Linguistics Today. 2011. BOURDIEU, Pierre. A economia das trocas linguísticas: o que falar quer dizer. São Paulo: Ed. USP, 1998.

Outline of a theory of practice. Cambrige University Press: Londres, [1983] 2004.

CALAFORRA, G. Lengua y poder en las situaciones de minorización linguística. Disponível em: <http://www.uv.es/calaforr/ CursColonia.pdf $>$. Acesso em 15.12.2016. 
CALVET, L. J. As políticas linguísticas. Pref. de Gilvan Muller de Oliveira. Trad. de Isabel de Oliveira Duarte, Jonas Tenfen e Marcos Bagno. São Paulo: Parábola Editorial/IPOL, 2007.

CAMERON, D. Desmythologizing Sociolinguistics, or why language does not reflect society. In: JOSEPH, J.; TAYLOR, T. (orgs.) Ideologies of Language. London, Routledge, 1990.

DELEUZE, G.; GUATTARI, F. Kafka: por uma literatura menor. Trad. de Júlio Castañon Guimarães. Rio de Janeiro: Editora Imago, 2002.

FANON, F. Os condenados da terra. Rio de Janeiro: Civilização Brasileira, p. 197-207, 1968.

FARACLAS, N. Nigerian pidgin and the languages of Southern Nigeria. In: Journal of Pidgin and Creole Languages, v. 3, n. 2, 1988. p. 177-197.

FIRMINO, G. A questão linguística na África pós-colonial: o caso do português e das línguas autóctones em Moçambique. Maputo: Promedia, 2002.

GEERTZ, C. A interpretação das culturas. Rio de Janeiro: LTC, 1989. Nova Luz sobre a Antropologia. Rio de Janeiro: Jorge Zahar, 2001.

LAGARES, X. C. Liberalismo linguístico e nacionalismo espanhol. In: PAVSLOSKI, E.; FRAGA, L. (orgs.). Linguagem, identidade e subjetividade no breve século XX: diálogos do VII CIEL. Blumenau: Nova Letra, p. 117-138, 2015.

MIGNOLO, W. Desobediência epistémica: retórica de la modernidad, lógica de la colonialidad, gramática de la descolonialidad. Buenos Aires: Del Siglo, 2010.

OBENG, S. G.; ECHU, G. West African languages in contact with European languages. In: Africa meets Europa: language contact in West Africa. New York: Nova Science Publishers, 2004.

ORTNER, S. Making Gender: The Politics and Erotics of Culture. Beacon Press, 1996.

PRAH, K. K. (Ed.) Rehabilitating African Languages. Cape Town: CASAS, 2002.

The Language of Development and the Development of Language in Contemporary Africa. In: Annual Conference of the American Association for Applied Linguistics (AAAL) in Chicago. March 26/29th 2011. 
SAHLINS, M. Cultura na Prática. Rio de Janeiro: Ed. da UFRJ, 2007. SAID, E. W. Cultura e imperialismo. São Paulo: Companhia de Bolso, 2011.

SANTOS, B. deS. Entre Próspero e Caliban: colonialismo, póscolonialismo e inter-identidade. In: Novos Estudos Cebrap, 2004. . A crítica da razão indolente. Para um novo senso comum: a ciência, o direito e a política na transição paradigmática. 8 . Ed. São Paulo: Cortez, 2011 [2000].

SANTOS, B. de S.; MENESES, M. P. (orgs.). Epistemologias do Sul. São Paulo: Cortez, 2010.

WA THIONGO, N. Decolonizing the Mind: the politics of language in African Literature. Harare: Zimbabwe Publishing House, 1987.

\begin{abstract}
Minority situation, minorified population, minor language: a reflection on the valuation of the status of languages in the context of linguistic contact

This paper presents a reflection on the centrality of the idea of domination and power in the field of Language Contact studies in particular as to the status of languages. Starting from the example of multilingualism in two postcolonial African countries, we aim at discussing the supremacy of some languages over others, which enables a certain verticality at the linguist's approach and in the assessing of the languages in contact.
\end{abstract}

Keywords: Linguistic Minorities. Multilingualism. Language Contact. 